\title{
BMJ Open Australian treatment outcome study: protocol for the 18-20-year follow-up of a prospective longitudinal cohort examining the natural history of heroin dependence and associated mortality, psychiatric and physical health, and health service use
}

To cite: Marel C, Mills K, Visontay $\mathrm{R}$, et al. Australian treatment outcome study: protocol for the 18-20-year follow-up of a prospective longitudinal cohort examining the natural history of heroin dependence and associated mortality, psychiatric and physical health, and health service use. BMJ Open 2020;10:e039226. doi:10.1136/ bmjopen-2020-039226

- Prepublication history for this paper is available online. To view these files, please visit the journal online (http://dx.doi org/10.1136/bmjopen-2020039226).

Received 08 April 2020 Revised 08 May 2020 Accepted 04 June 2020

Check for updates

(c) Author(s) (or their employer(s)) 2020. Re-use permitted under CC BY-NC. No commercial re-use. See rights and permissions. Published by BMJ.

For numbered affiliations see end of article.

Correspondence to

Dr Christina Marel;

christina.marel@sydney.edu.au

Christina Marel (D) , ${ }^{1}$ Katherine Mills, ${ }^{1}$ Rachel Visontay, ${ }^{1}$ Jack Wilson, ${ }^{1}$ Shane Darke, ${ }^{2}$ Joanne Ross, ${ }^{2}$ Tim Slade, ${ }^{1}$ Paul S Haber, ${ }^{3,4}$ Katherine Haasnoot, ${ }^{1}$ Madeleine Keaveny, ${ }^{1}$ Chris Tremonti, ${ }^{4}$ Maree Teesson ${ }^{1}$

\section{ABSTRACT}

Introduction 0pioid dependence is a global health priority, currently making the biggest contribution to drug-related deaths. The chronic, long-term persistence of heroin dependence over the life course requires investigation in prospective longitudinal studies, to better understand patterns and predictors of remission and relapse, as well as the impact of changes in substance use on a range of physical and mental health outcomes. Such knowledge is critical in order to identify modifiable risk factors that can be targeted for intervention. Crucial unanswered questions include the following: What are the long-term rates of mortality? What are the longterm patterns and predictors of heroin use, remission, psychiatric health and health service use? What are the long-term physical health consequences of heroin use? Methods and analysis The 18-20-year follow-up of the Australian Treatment Outcome Study (ATOS) cohort will examine the natural history of heroin dependence of an existing cohort of 615 people with heroin dependence, who were recruited into the study in 2001-2002. Five waves of follow-up interviews have since been completed, at 3-month, 1-year, 2-year, 3-year and 10-11-year postbaseline. At the 18-20-year follow-up, the ATOS cohort is (on average) approaching their 50 s and an average of 30 years have passed since they first used heroin. The 18-20-year follow-up will consist of: (1) a structured interview; (2) physical health assessment; and (3) data linkage. The results of this follow-up will improve our understanding and management of age-related disorders in this population, which if not addressed in the immediate future, has the capacity to overwhelm treatment centres and aged care facilities.

Ethics and dissemination Ethical approval has been granted for the study (Sydney Local Health District Royal Prince Alfred Zone, Human Research Ethics Committee X18-0512 \& HREC/18/RPAH/733). The results of the study will be disseminated through published manuscripts,
Strengths and limitations of this study

A strength of this study is that we will be able to capture the dynamic long-term patterns of heroin use, remission, psychiatric health and health service use over 18-20 years, and associated risk factors.

- For the first time, we will be able to investigate the physical health consequences associated with longterm heroin dependence.

- A further strength is that we will be able to investigate whether static and dynamic risk factors affect the developmental course of each outcome.

- While attrition bias represents a major threat to the validity of cohort studies, the study has achieved excellent retention rates to date.

bulletins and technical reports, as well as conference, seminars, webinar and workshop presentations.

\section{INTRODUCTION}

Opioid dependence is associated with exceedingly high levels of morbidity and mortality, and a greater burden of disease than any other illicit drug class. ${ }^{1-5}$ Despite recent concern surrounding increased use of methamphetamine and new psychoactive substances, opioids remain the biggest contributor to drugrelated deaths worldwide, ${ }^{2}$ with people who use heroin dying at a rate 15 times that of their non-using peers. ${ }^{5}$ Moreover, the global burden associated with heroin dependence continues to rise, increasing by $74 \%$ between $1990-2010,{ }^{1}$ of which only $28 \%$ was attributable to population growth. ${ }^{6}$ An estimated 29.2 million people 
worldwide used heroin in $2017,^{2}$ and of those, almost one in two $(45 \%)$ will have developed an opioid use disorder. ${ }^{7}$

Heroin dependence is commonly conceptualised as a chronic relapsing condition. ${ }^{4}$ Surprisingly, little is known, however, about its long-term course and natural history, largely due to the absence of prospective longitudinal cohort studies beyond 10 years. In contrast with acute conditions, which may be relatively brief and severe, chronic diseases have typically been defined as persistent, long-lasting conditions, often with recurrent episodes of relapse or remission over a number of years, which can differ in duration and intensity, and impact the person's quality of life. ${ }^{8-10}$ As argued by Fleury et al, if heroin dependence falls within this definition of chronicity, it follows that treatment for heroin dependence should also be long-term, continuous and varying in intensity, with longitudinal treatment outcome studies used to assess key findings. ${ }^{10}$

Of the few longitudinal studies that do exist, long-term outcomes among people with heroin dependence have been demonstrated to be overwhelmingly poor, with most following a chronic disabling trajectory leading to premature death. ${ }^{1-13}$ Heroin dependence has been associated with poorer physical $^{5}{ }^{14}$ and psychological health, ${ }^{15-18}$ particularly among those who are older. ${ }^{15} 19$ The general pattern appears to be one of accelerated ageing, whereby young to middle-aged heroin users present with physical health problems (eg, hypertension, arthritis, osteoporosis and other age-related degenerative diseases) more typical of the elderly. 1520

While longitudinal cohort studies provide a unique opportunity to examine patterns and predictors of remission and relapse as well as the impact of changes in substance use on a range of physical and mental health outcomes, few cohort studies of heroin dependence exist beyond 10 years, and few have examined other health outcomes. ${ }^{31121-31}$ The very high mortality rates observed in international cohorts (typically $25 \%-50 \%$ deceased 20 years after baseline),${ }^{4}$ coupled with high rates of attrition (typically 20\%-30\% excluding mortality), ${ }^{4}$ make comparisons between studies and over time even more complex.

Recent research has highlighted that the mortality rates of Australians with heroin dependence are lower than observed in other international cohorts, meaning that an increasing number of Australians with a history of heroin dependence are living longer. Little is known about their physical health and disease profile as they age, with research largely limited to cross-sectional studies. ${ }^{40}$ It is unclear how patterns of heroin use across the lifespan impact on longterm physical health, especially into later adulthood, when there is a greater risk of disease, disability and mortality.

An Australian data linkage study examining mortality between 1980 and 2006 among people who received methadone between 1980 and 1985 found that while the leading causes of death were initially related to drug use, physical illnesses such as cirrhosis and cancer became increasingly more dominant over time. ${ }^{32}$ Long-term opiate use has also been associated with a range of cardiovascular risk factors, which may be exacerbated by the consumption of medications typically prescribed to people with heroin dependence (eg, methadone, antidepressants, antipsychotics and antibiotics). ${ }^{33-35}$

The 18-20-year follow-up of the Australian Treatment Outcome Study (ATOS), a prospective longitudinal study of people with heroin dependence, responds to the urgent need for high-quality studies to better understand the natural history of heroin dependence over the long term. Several key findings have emerged from ATOS to date, including (1) The annual mortality rate of Australians with heroin dependence $(<1 \%)$ is less than observed among cohorts in other parts of the world (highest rates are in Asia (3\%), followed by Western Europe (2\%-3\%) and North America $(1 \%-2 \%)){ }^{436}$ (2) Trajectories of heroin use and remission may be more heterogeneous than previously thought, with six distinctive trajectories of heroin use identified over 10-11 years ${ }^{37}$, compared with three or four found in other studies. ${ }^{11-13}$ (3) Long-term stable retention in treatment is key to achieving positive outcomes. ${ }^{16}$ ATOS has collected comprehensive data from participants regarding treatment exposure over the course of the study allowing us to examine movement in and out, and between, treatment modalities. (4) Major depression was a robust and enduring predictor of poorer outcome for every indicator examined across the 10-11 years, highlighting the need for targeted interventions. ${ }^{4}$ (5) High rates of trauma exposure (92\%), particularly childhood trauma, and post-traumatic stress disorder (PTSD; 41\%) were observed, ${ }^{17}$ highlighting trauma and PTSD to be a major, but largely hidden, clinical issue for Australians with heroin dependence.

However, critical questions remain, including What are the long-term rates of mortality? What are the long-term patterns and predictors of heroin use, remission, psychiatric health and health service use? What are the long-term physical health consequences of heroin use? The 18-20-year follow-up of ATOS will address these critical unanswered questions at a time in a global climate when many countries are in the grip of an opioid epidemic.

\section{METHODS AND ANALYSIS}

The original ATOS cohort of 615 was initially recruited into the study in 2001-2002; 535 (87\%) of whom were entering treatment for heroin dependence (201 maintenance therapies, 201 detoxification and 133 residential rehabilitation), and 80 of whom were not in treatment (recruited from needle and syringe programmes). At the time of recruitment, participants were on average, 29 years of age (range: 18-56), and two-thirds (66.2\%) male. The cohort has been followed up on five occasions with exceptional follow-up rates (3 months: $89 \%, \mathrm{n}=549$; 1 year: $80 \%, \mathrm{n}=495$; 2years: $76 \%, \mathrm{n}=469$; 3 years: $70 \%, \mathrm{n}=429$ and $10-11$ years: $70 \%, \mathrm{n}=431)^{16}$; over $96 \%$ of the cohort has completed at least one follow-up interview. The 18-20-year follow-up is currently underway (as of September 2019).

The ATOS 18-20-year follow-up comprises a structured follow-up interview, a physical health assessment and a data linkage component. Attempts to locate and follow-up the 
ATOS cohort began in September 2019, when participants were on average 47 years of age. We will continue to use our robust methods for locating participants. ${ }^{38}$ Systematic steps will be undertaken by the research team to contact participants using comprehensive locator information collected at baseline and updated at each follow-up interview. To locate hard-to-find participants, targeted placement of advertisements in drug treatment services and other locations that may be accessed by the cohort will be undertaken as well as searches of publicly available sources of information. We anticipate that a follow-up rate of at least $60 \%(\mathrm{n}=369)$ will be achieved at $18-20$ years.

\section{Outcomes and assessments}

Eighteen-year to twenty-year outcomes will be assessed using a combination of: (1) a structured interview; (2) physical assessment; and (3) data linkage. Separate consents will be obtained for the structured interview, physical health assessments and data linkage components.

\section{Structured interview}

Interviews will be conducted in person at a time and place convenient to participants or over the phone. The study's research assistants will administer a survey of approximately 90 min duration, consisting of standardised measures with established psychometric properties. These measures have been previously used in earlier follow-ups of the ATOS cohort. In order to maximise participant recall, interviews will be administered with the use of the life chart approach, ${ }^{39}$ based on the well-validated timeline followback (TLFB) method. ${ }^{40}$ TLFB anchors interview questions to significant events in participants' lives (eg, marriage, divorce, births, deaths and incarceration).

Demographic data, including participants' age, sex, main source of income and accommodation, will be collected, consistent with previous ATOS interviews. ${ }^{16}$ Heroin and other substance use, injection-related health, needle sharing and criminality will be measured using the Opiate Treatment Index. ${ }^{41}$ Periods of abstinence will be assessed using the TLFB approach. ${ }^{39}$ There is a vast literature which supports the validity and reliability of self-reported drug use. $^{42}$ The self-report of heroin use among the ATOS cohort was previously validated against hair analysis conducted at the 3-month follow-up on a random sample of 10\% $(n=61)$. Overall agreement between any self-reported heroin use in the preceding month and the presence of morphine in hair was $75 \%$ (kappa $=0.51$ ). In $15 \%$ of cases, heroin use was reported by participants, but morphine was not detected in their hair. ${ }^{43}$

Diagnoses of heroin dependence and psychiatric disorders, including major depression and PTSD, will be assessed using the Composite International Diagnostic Interview and Diagnostic Interview Schedule v2.1. ${ }^{44}$ Complex PTSD will be assessed using the International Trauma Questionnaire. ${ }^{45}$ General physical and mental health will be measured using the Short Form 12. ${ }^{46}$ Pain will be assessed using the Brief Pain Inventory, ${ }^{46}$ and a Healthy Eating Index will assess patterns of healthy eating. The health services utilisation form, developed by the Centre for Health Economics Research and Evaluation (University of Sydney) for ATOS, will be used to measure prescribed medications, ambulance use, hospital services, general practitioner visits and dental, specialist and psychological services in the preceding month. Participants interviewed in person will be administered the Mini-Addenbrooke's Cognitive Examination ${ }^{47}$ to assess for cognitive impairment.

\section{Physical health assessment}

In addition to the structured interview, consenting participants living in greater Sydney will be invited to undergo a comprehensive structured medical assessment and physical examination with an advanced trainee physician at Royal Prince Alfred Hospital, Sydney. We conservatively estimate that approximately 150 participants $(40 \%)$ who complete the structured interview will consent to undergo the medical assessment. Investigations will be conducted in line with current guidelines to screen for blood-borne viruses (hepatitis B surface antigen, HIV and hepatitis C virus antibodies), liver disease (liver function tests and fibroscan), kidney disease (urea and electrolytes, and dip-stick urinalysis), endocrine abnormalities, including hypogonadism, metabolic syndrome and osteopenia (testosterone, sex hormone binding globulin, oestrogen, luteinising hormone, follicle-stimulating hormone, prolactin, thyroidstimulating hormone, free thyroxine, osteocalcin, fasting glucose, 25-hydroxy vitamin $\mathrm{D}$, insulin and C-peptide level, haemoglobin A1c, cortisol, adrenocorticotropic hormone, dihydroepiandrosterone and insulin-like growth factor-1), respiratory disease (pre-bronchodilator and post-bronchodilator spirometry, oximetry and \%carboxyhaemoglobin by Smokerlyzer), cardiac risks and dysfunction (triglycerides, cholesterol ECG and cardiac CT for coronary artery calcium scoring) and immune and inflammatory markers (C-reactive protein, erythrocyte sedimentation rate and total lymphocyte count).

\section{Data linkage}

Probabilistic matching for the entire cohort $(\mathrm{n}=615)$ will be undertaken to collect data on (1) mortality and cause of death from the Australian Institute of Health and Welfare (AIHW) National Death Index and (2) health service utilisation (rates, reasons for attendance/admission using International Classification of Diseases, 9th revision (ICD-9) and International Classification of Diseases, 10th revision, Australian Modification (ICD-10-AM) codes, length of stay and reason for discharge) from multiple databases held by the New South Wales' Centre for Health Record Linkage, including pharmaceutical drugs of addiction system, admitted patient data collection, emergency department data collection, mental health ambulatory data collection and NSW ambulance, as well as the AIHW Medicare Benefits Scheme and Pharmaceutical Benefits Scheme.

\section{Analysis}

The analytical approaches to be used to answer each research question are described below. 
What are the long-term rates of mortality?

Crude mortality rates per 1000 person years and standardised mortality ratios will be calculated with $95 \%$ CIs, with reference to age-specific death rates in the Australian population. Years of potential life lost will be calculated using two criteria: years lost prior to age 65 (Centre for Disease Control and Prevention criteria) and years lost prior to average life expectancy (specified for gender and the year in which the death occurred). Cox regression models will be fitted to the data in order to identify predictors of mortality. Based on mortality rates between 2001 and 2015, we expect 96 deaths to have occurred at 20 years (which is equivalent to an anticipated event rate of 0.15 ).

What are the long-term patterns and predictors of heroin use, remission, psychiatric health and health service use?

Group-based trajectory modelling (GBTM) will be used to capture the dynamic longitudinal trajectories of heroin use, remission, psychiatric health and health service use (modelled separately) across the 18-20 years. This approach will enable us to examine the heterogeneity of trajectory patterns, and risk factors for group membership, associated with heroin use, remission, psychiatric health and health service use over the long term. GBTM will also allow us to examine whether events that occur during the course of a trajectory (dynamic or time-variant, and potentially modifiable, risk factors) alter the trajectory itself. A GBTM approach also allows for examination of dual trajectories of related behaviours, which develop simultaneously, such as heroin use and psychiatric health. These analyses will provide critical information to help identify those at greater risk of poor outcomes, and guide the development of targeted interventions that can be delivered at crucial time points. ${ }^{12}$

\section{What are the long-term physical health consequences of heroin} use?

Cross-sectional analyses, including linear and logistic regression, will be undertaken to examine associations between static and dynamic risk factors across follow-up on physical health assessments undertaken at 18-20years. In particular, we will be examining associations between participants' long-term drug use and trajectory patterns with later pathology.

\section{Ethics and dissemination}

Ethical approval has been obtained for the study (Sydney LHD RPA Zone HREC X18-0512 \& HREC/18/RPAH/733). We will disseminate study results through published manuscripts, bulletins and technical reports, conference, seminar, webinar and workshop presentations. The data contributing to this study come from a third party and are not publicly available, even in de-identified format. Further inquiries can be submitted to the corresponding author.

\section{DISCUSSION}

The extension of the ATOS study to 18-20years will provide the opportunity to gain a greater understanding of the natural history of heroin use in terms of mortality, remission, psychiatric and physical health, and health service utilisation. Findings will highlight critical windows for identifying periods when risk may be elevated for some people. The wealth of data collected allows for: (1) a detailed longitudinal examination of the complex relationships between substance use, mental health and physical health outcomes; (2) defining long-term unmet treatment needs of those disabled by heroin dependence with respect to mental and physical health and (3) identification of potential intervening variables that may modify illness course to guide public health and treatment responses.

The ageing ATOS cohort provides a rare opportunity to advance knowledge across these domains. Participants are approaching their $50 \mathrm{~s}$, and on average, 30 years have passed since they first used heroin. In answering critical questions, the 18-20-year follow-up of ATOS aims to improve understanding and management of age-related disorders in this population, which if not addressed in the immediate future, has the capacity to overwhelm treatment centres and aged care facilities. Self-report combined with physical health assessments and sophisticated data linkage will allow us to address significant gaps in knowledge, guide more effective interventions and public health responses internationally, and ultimately reduce the considerable burden attributable to heroin dependence for the individual, their families and the broader community.

\section{Author affiliations}

${ }^{1}$ Matilda Centre for Research in Mental Health and Substance Use, University of Sydney, Sydney, New South Wales, Australia

${ }^{2}$ National Drug and Alcohol Research Centre, UNSW, Sydney, New South Wales, Australia

${ }^{3}$ University of Sydney Addiction Medicine, Royal Prince Alfred Hospital, Camperdown, New South Wales, Australia

${ }^{4}$ Drug Health Services, Sydney Local Health District, Camperdown, New South Wales, Australia

Acknowledgements The authors thank Rachel Visontay, Jack Wilson, Madeleine Keaveny and Katherine Haasnoot, and all the ATOS participants.

Contributors CM, KM, SD, JR, TS, PSH and MT contributed significantly to the planning, conceptualisation, design and successful funding of the 18-20-year follow-up of the Australian Treatment Outcome Study (ATOS). RV and JW drafted the initial version of this manuscript, which was based on the ATOS study protocol, written by $\mathrm{CM}$ and $\mathrm{KM}$. CM and KM critically revised the manuscript and made substantial content contributions. JW, KH, MK and CT are contributing significantly to the acquisition of the data. All authors gave final approval for this version of the manuscript to be submitted for publication.

Funding This work was funded by an Australian National Health and Medical Research Council (NHMRC) Project Grant number APP1147212, and supported by NHMRC Fellowships to Christina Marel, Katherine Mills and Maree Teesson.

Competing interests None declared.

Patient and public involvement Patients and/or the public were not involved in the design, or conduct, or reporting, or dissemination plans of this research.

Patient consent for publication Not required.

Provenance and peer review Not commissioned; peer reviewed for ethical and funding approval prior to submission.

Open access This is an open access article distributed in accordance with the Creative Commons Attribution Non Commercial (CC BY-NC 4.0) license, which permits others to distribute, remix, adapt, build upon this work non-commercially, and license their derivative works on different terms, provided the original work is 
properly cited, appropriate credit is given, any changes made indicated, and the use is non-commercial. See: http://creativecommons.org/licenses/by-nc/4.0/.

\section{ORCID iD}

Christina Marel http://orcid.org/0000-0002-1371-6986

\section{REFERENCES}

1 Degenhardt L, Whiteford HA, Ferrari AJ, et al. Global burden of disease attributable to illicit drug use and dependence: findings from the global burden of disease study 2010. Lancet 2013;382:1564-74.

2 United Nations Office on Drugs and Crime. World drug report 2019. New York: UN, 2019

3 Stoové MA, Dietze PM, Aitken CK, et al. Mortality among injecting drug users in Melbourne: a 16-year follow-up of the Victorian injecting cohort study (VICS). Drug Alcohol Depend 2008;96:281-5.

4 Hser Y-I, Evans E, Grella C, et al. Long-Term course of opioid addiction. Harv Rev Psychiatry 2015;23:76-89.

5 Hser Y-I, Mooney LJ, Saxon AJ, et al. High mortality among patients with opioid use disorder in a large healthcare system. $J$ Addict Med 2017;11:315-9.

6 Degenhardt L, Charlson F, Mathers B, et al. The global epidemiology and burden of opioid dependence: results from the global burden of disease 2010 study. Addiction 2014;109:1320-33.

7 Marel C, Sunderland M, Mills KL, et al. Conditional probabilities of substance use disorders and associated risk factors: progression from first use to use disorder on alcohol, cannabis, stimulants, sedatives and opioids. Drug Alcohol Depend 2019;194:136-42.

8 Australian Institute of Health and Welfare. Chronic disease 2019. Available: https://www.aihw.gov.au/reports-data/health-conditionsdisability-deaths/chronic-disease/overview [Accessed 4 Mar 2020].

9 Bernell S, Howard SW. Use your words carefully: what is a chronic disease? Front Public Health 2016;4:159.

10 Fleury M-J, Djouini A, Huỳnh C, et al. Remission from substance use disorders: a systematic review and meta-analysis. Drug Alcohol Depend 2016;168:293-306.

11 Grella CE, Lovinger K. 30-Year trajectories of heroin and other drug use among men and women sampled from methadone treatment in California. Drug Alcohol Depend 2011;118:251-8.

12 Hser Y-I, Huang D, Chou C-P, et al. Trajectories of heroin addiction: growth mixture modeling results based on a 33-year follow-up study. Eval Rev 2007;31:548-63.

13 Hser Y-I, Longshore D, Anglin MD. The life course perspective on drug use: a conceptual framework for understanding drug use trajectories. Eval Rev 2007;31:515-47.

14 Theodorou S, Haber PS. The medical complications of heroin use. Curr Opin Psychiatry 2005;18:257-63.

15 Rosen D, Smith ML, Reynolds CF. The prevalence of mental and physical health disorders among older methadone patients. Am J Geriatr Psychiatry 2008;16:488-97.

16 Teesson M, Marel C, Darke S, et al. Long-Term mortality, remission, criminality and psychiatric comorbidity of heroin dependence: 11year findings from the Australian treatment outcome study. Addiction 2015;110:986-93.

17 Mills KL, Lynskey M, Teesson M, et al. Post-Traumatic stress disorder among people with heroin dependence in the Australian treatment outcome study (ATOS): prevalence and correlates. Drug Alcohol Depend 2005;77:243-9.

18 Grella CE, Lovinger K. Gender differences in physical and mental health outcomes among an aging cohort of individuals with a history of heroin dependence. Addict Behav 2012;37:306-12.

19 Lofwall MR, Brooner RK, Bigelow GE, et al. Characteristics of older opioid maintenance patients. J Subst Abuse Treat 2005;28:265-72.

20 Darke S. The life of the heroin user: typical beginnings, trajectories and outcomes. Cambridge: Cambridge University Press, 2011.

21 Comiskey C, Stapleton R. Treatment pathways and longitudinal outcomes for opiate users: implications for treatment policy and planning. Drugs: Education, Prevention and Policy 2010;17:707-17.

22 Flynn PM, Joe GW, Broome KM, et al. Recovery from opioid addiction in DATOS. J Subst Abuse Treat 2003;25:177-86.

23 Goldstein A, Herrera J. Heroin addicts and methadone treatment in Albuquerque: a 22-year follow-up. Drug Alcohol Depend 1995;40:139-50.
24 Gossop M, Marsden J, Stewart D, et al. The National treatment outcome research study (NTORS): 4-5 year follow-up results. Addiction 2003;98:291-303.

25 Horyniak D, Higgs P, Jenkinson R, et al. Establishing the Melbourne injecting drug user cohort study (mix): rationale, methods, and baseline and twelve-month follow-up results. Harm Reduct $J$ 2013;10:11.

26 Hser Y-I. Predicting long-term stable recovery from heroin addiction: findings from a 33-year follow-up study. J Addict Dis 2007;26:51-60.

27 Hser Y-I, Evans E, Huang D, et al. Comparing the dynamic course of heroin, cocaine, and methamphetamine use over 10 years. Addict Behav 2008;33:1581-9.

28 Jimenez-Treviño L, Saiz PA, García-Portilla MP, et al. A 25-year follow-up of patients admitted to methadone treatment for the first time: mortality and gender differences. Addict Behav 2011;36:1184-90.

29 Oppenheimer E, Stimson GV, Thorley A. Seven-Year follow-up of heroin addicts: abstinence and continued use compared. $\mathrm{Br} \mathrm{Med} \mathrm{J}$ 1979;2:627-30.

30 Rathod NHR, Addenbrooke WM, Rosenbach AF. Heroin dependence in an English town: 33-year follow-up. Br J Psychiatry 2005;187:421-5.

31 Hser YI, Hoffman V, Grella CE, et al. A 33-year follow-up of narcotics addicts. Arch Gen Psychiatry 2001;58:503-8.

32 Gibson A, Randall D, Degenhardt L. The increasing mortality burden of liver disease among opioid-dependent people: cohort study. Addiction 2011;106:2186-92.

33 Taylor DM. Antipsychotics and QT prolongation. Acta Psychiatr Scand 2003;107:85-95.

34 Chugh SS, Socoteanu C, Reinier K, et al. A community-based evaluation of sudden death associated with therapeutic levels of methadone. Am J Med 2008;121:66-71.

35 Martell BA, Arnsten JH, Krantz MJ, et al. Impact of methadone treatment on cardiac repolarization and conduction in opioid users. Am J Cardiol 2005;95:915-8.

36 Degenhardt L, Bucello C, Mathers B, et al. Mortality among regular or dependent users of heroin and other opioids: a systematic review and meta-analysis of cohort studies. Addiction 2011;106:32-51.

37 Teesson M, Marel C, Darke S, et al. Trajectories of heroin use: 10-11year findings from the Australian treatment outcome study. Addiction 2017;112:1056-68.

38 Marel C, Mills K, Darke S, et al. Can we predict retention in longitudinal studies of substance use? findings from the Australian treatment outcome study. Addict Behav 2015;51:38-43.

39 Hunt C, Andrews G. Comorbidity in the anxiety disorders: the use of a life-chart approach. J Psychiatr Res 1995;29:467-80.

40 Sobell LC, Sobell MB. Timeline Follow-Back: A Technique for Assessing Self-Reported Alcohol Consumption. In: Litten RZ, Allen JP, eds. Measuring alcohol consumption: psychosocial and biochemical methods. New York: Springer Science and Business, 1992: 41-72.

41 Darke S, Hall W, Wodak A, et al. Development and validation of a multi-dimensional instrument for assessing outcome of treatment among opiate users: the opiate treatment index. $\mathrm{Br} J$ Addict 1992;87:733-42.

42 Darke S. Self-Report among injecting drug users: a review. Drug Alcohol Depend 1998;51:253-63.

43 Ross J, Lynskey M, Teesson M, et al. Three month outcomes for the treatment of heroin dependence: findings from the Australian treatment outcome study (ATOS), New South Wales. NDARC technical report. Australia: UNSW, 2003.

44 World Health Organization. Composite international diagnostic interview. Geneva: World Health Organization, 1996.

45 Cloitre M, Shevlin M, Brewin CR, et al. The International trauma questionnaire: development of a self-report measure of ICD-11 PTSD and complex PTSD. Acta Psychiatr Scand 2018;138:536-46.

46 Ware J, Kosinski M, Keller SD. A 12-Item short-form health survey: construction of scales and preliminary tests of reliability and validity. Med Care 1996;34:220-33.

47 Hsieh S, McGrory S, Leslie F, et al. The Mini-Addenbrooke's cognitive examination: a new assessment tool for dementia. Dement Geriatr Cogn Disord 2015;39:1-11. 